\title{
O ENVELHECIMENTO DO PROFESSOR DE EDUCAÇÃO FÍSICA E SUA PRÁTICA PROFISSIONAL: SIGNIFICADOS ATRIBUÍDOS AO CORPO E À SAÚDE1
}

\author{
Alan Camargo Silva \\ Universidade Federal do Rio de Janeiro, Rio de Janeiro, Rio de Janeiro, Brasil \\ Alexandre Palma \\ Universidade Federal do Rio de Janeiro, Rio de Janeiro, Rio de Janeiro, Brasil \\ Sílvia Maria Agatti Lüdorf \\ Universidade Federal do Rio de Janeiro, Rio de Janeiro, Rio de Janeiro, Brasil
}

\begin{abstract}
Resumo
Sabe-se que os significados atribuídos ao corpo e à saúde pelo profissional de Educação Física podem não ser homogêneos ao longo da carreira docente. O objetivo da pesquisa foi analisar e discutir se (e com quais significados) o corpo e a saúde emergem nas relações entre o envelhecimento do professor de Educação Física e sua prática profissional. Os dados foram obtidos por meio de 22 entrevistas semiestruturadas realizadas com professores atuantes em escolas e academias. Detectou-se que enquanto na academia a prática profissional deixou de estar voltada à estética corporal e atualmente focou-se para a saúde e qualidade de vida, no âmbito escolar, o aspecto social se sobrepôs à discussão sobre saúde, provavelmente pela mudança do perfil do aluno ao longo dos anos.

Palavras-chave: Envelhecimento. Educação Física e Treinamento. Corpo Humano. Saúde.
\end{abstract}

\section{Introdução}

— studar o corpo e a saúde na área de Educação Física significa Econsiderar um conjunto complexo de referenciais teóricos tanto da área biomédica como das Ciências Humanas e Sociais. De acordo com Carvalho (2001), ao longo do tempo, saúde significava ausência de doença, completo bem-estar físico-psíquico-social, estar em um padrão "normal", ou ainda disposição de superação das adversidades físicas, psíquicas e sociais. Em uma perspectiva semelhante, Minayo (2006, p. 94) afirma que saúde "é um termo bastante genérico, portador de muitos significados e utilizado, segundo interesses específicos, nos mais diferentes sentidos.”. Tratam-se, portanto, de noções cons-

1-O presente trabalho contou com apoio financeiro do auxílio APQ1 da FAPERJ. 
truídas histórica e culturalmente que sustentam as representações dos professores $^{2}$ de Educação Física.

Neste texto, sem negar as importantes explicações dos referenciais biomédicos, baseando-se em Le Breton (2003), compreende-se o corpo como uma construção sociocultural e a saúde como um objeto complexo que deve ser entendido pela sua totalidade de modo ampliado por ser um fenômeno constituído por aspectos multidimensionais, articulados e dinâmicos, representados por influências sociais, políticas, institucionais e ideológicas (ALMEIDA FILHO, 2011).

Nesse contexto, é preciso levar em consideração o momento da carreira profissional, as necessidades, as experiências e a forma como o professor interpreta e dá significado à sua prática profissional que podem ser diferenciadas ao longo dos anos (FOLLE et al., 2009). O processo de envelhecimento no trabalho pode ser ressignificado a partir de uma fonte de interesse de aprendizado crescente e constantemente renovado (BEAUVOIR, 1976).

Se a profissão de Educação Física, em parte, se vincula à ideia de realizar intervenções com a prática corporal voltada à saúde, é preciso conhecer, portanto, como a própria saúde e o corpo são concebidos pelos profissionais que envelhecem atuando na área. Diante das diferentes representações relativas ao corpo e das variadas concepções de saúde que residem na área da Educação Física, torna-se essencial investigar como o professor apropria-se dessas noções, ou ainda, as aborda em sua prática profissional, uma vez que, ao longo da carreira, o professor adota múltiplas formas de pensar e de agir profissionalmente (STANO, 2001).

Analisar a carreira do professor de Educação Física e a sua atuação com o corpo e a saúde significa considerar que os conhecimentos e as experiências acumulados podem influenciar e diversificar a intervenção profissional com seus alunos diferentemente daqueles que estão no início de carreira. Aproximar-se da lógica dos aspectos constitutivos do pensar e do agir do professor ao longo da carreira docente, isto é, do conjunto de valores, crenças e normas que rege a prática profis-

2-Embora atualmente haja a distinção entre professor e profissional de Educação em função da diferença entre as formações iniciais, isto é, licenciatura e bacharelado (ou graduação), respectivamente; optou-se por utilizar o termo professor, na medida em que grande parte dos sujeitos pesquisados se formou antes de tal divisão, estando habilitados para atuar em diversos âmbitos de trabalho. 
sional dos professores ao envelhecerem, facilita a compreensão das suas ações no/para o campo da saúde.

Petry e Garces (2009) detectaram que grande parte dos professores ao envelhecer almeja para os alunos cuidados em busca de um "corpo saudável". No entanto, ainda são escassos os estudos concernentes aos significados atribuídos ao corpo e à saúde, sobretudo a partir da prática profissional do professor de Educação Física ao envelhecer. Desse modo, o objetivo da presente pesquisa é analisar e discutir se (e com quais significados) o corpo e a saúde emergem nas relações entre o envelhecimento do professor de Educação Física e sua prática profissional.

\section{Procedimentos metodológicos}

A presente pesquisa está pautada na abordagem qualitativa por empreender interpretações sobre os significados que os sujeitos concebem a partir do contexto em que estão inseridos (TURATO, 2011). Optou-se pela construção da amostragem por variedade de tipos delineada por Turato (2011), que permite capturar eventuais semelhanças e diferenças entre os sujeitos. A partir de uma determinada característica comum a todos os indivíduos, foram selecionados sujeitos inseridos na mesma profissão ou ocupação; no caso, professor de Educação Física escolar e de academia de ginástica.

Foram investigados 22 professores de Educação Física ${ }^{3}$ formados nas décadas de 80 e 90, aproximadamente há 20 anos no mercado de trabalho, sendo 14 professores ( 9 pós-graduados) e 8 professoras (6 pós-graduadas) na faixa etária entre 40 e 60 anos (média de idade 49,81 anos) da cidade do Rio de Janeiro. Dos 22 professores, 10 atuavam em academias de ginástica, $11 \mathrm{em}$ escolas e $1 \mathrm{em}$ ambos os âmbitos de trabalho. Privilegiou-se o professor estar ativo no mercado de trabalho, uma vez que a proximidade da vivência profissional, possivelmente, interfere nas lembranças, intenções e opiniões significativamente. Os professores inativos ou aposentados poderiam estar distantes dessa prática.

A entrevista semiestruturada foi utilizada como instrumento de coleta de dados, pois possibilita que as concepções sobre o próprio envelhecimento e os significados atribuídos ao corpo e à saúde na prática profissional sejam pontuados. Durante os meses de Setem-

3-Identificados por P1 a P22.

Pensar a Prática, Goiânia, v. 16, n. 3, p. 619-955, jul./set. 2013 819 
bro/2009 a Novembro/2010, as entrevistas foram gravadas em ambiente reservado para serem posteriormente transcritas para análise. $\mathrm{O}$ roteiro de questões continha uma primeira parte referente ao perfil do sujeito (estado civil, formação acadêmica e âmbitos de trabalho) e em seguida, perguntas norteadoras ${ }^{4}$ da entrevista.

O tratamento dos dados foi realizado com uma pré-análise através da "leitura flutuante", destacando as primeiras aproximações interpretativas. Em seguida, foi realizada a análise de conteúdo proposta por Turato (2011), proporcionando a elaboração de categorias baseadas nos princípios de repetição e de relevância. As principais categorias que emergiram do processo de análise foram: "saúde como se fosse um objeto a ser adquirido e/ou moldável", "aspecto social" e "qualidade de vida associada à saúde".

Os professores assinaram o Termo de Consentimento Livre e Esclarecido, conforme os preceitos éticos para pesquisas realizadas com seres humanos. O presente estudo foi autorizado pelo Comitê de Ética em Pesquisa do Instituto de Estudos em Saúde Coletiva da Universidade Federal do Rio de Janeiro (processo 52/2008 e parecer 04/2009).

\section{Apresentação e discussão dos dados}

Em primeiro lugar, longe de ignorar a pluralidade epistemológica da área, nota-se que os professores comentaram como a Educação Física está posicionada especificamente em relação à saúde:

Continuo achando, eu continuo preocupado com relação a como é colocado a nossa profissão, entendeu? Assim, ficou muito li-

4-1. Com o que trabalhou/tem trabalhado durante esses anos?; 2. Você percebe alguma diferença na sua prática profissional no início da carreira e na de agora?; 3. No trabalho com seus alunos, o que tem norteado a sua prática profissional?; 4. O que significa envelhecer para você?; 5. Você tem alguma preocupação em relação ao seu envelhecimento? Qual(is)?; 6. De que maneira o envelhecimento se relaciona com sua vida profissional?; 7. Qual aspecto você mais valoriza no seu corpo? Por quê? Neste trabalho, optou-se por privilegiar as questões de número 1, 2 e 3 pelo fato da análise se voltar primordialmente ao aspecto profissional. As outras questões, mais voltadas à dimensão pessoal, serviram para subsidiar as noções de envelhecimento dos professores que inevitavelmente atravessaram/ permearam as respostas vinculadas ao trabalho, como já pôde ser visto em outra oportunidade (SILVA; LÜDORF, 2012). 
gado a uma área Biomédica. Quando teria que vir mais para (área de) Humanas, uma coisa mais de educador do que uma coisa de técnico [...] vejo que não "tá" caminhando "pra" isso, cada ano, cada vez "tá" mais técnico o negócio. (P2 - Professor de academia de ginástica e de escola, 50 anos)

A propaganda da saúde, do correr, do nadar, de fazer a prática esportiva, então, isso "tá" possibilitando, né? "Tá" aumentando o mercado de trabalho, eu vejo dessa forma hoje, sinceramente, de maneira positiva. (P3 - Professor de escola, 47 anos)

Mesmo vivenciando um tempo considerável de carreira, o que poderia simbolizar certo desgaste profissional, os professores estão conectados com a realidade da área, no que diz respeito às diferentes ideias vinculadas à saúde. Como foi possível perceber de forma ilustrativa nos trechos supracitados, ora as relações entre a Educação Física e a saúde são vistas de forma mais pessimista, como, por exemplo, no sentido de que está privilegiando primordialmente os pressupostos biomédicos, ora otimista, haja vista que a suposta divulgação do exercitar-se para a saúde amplia a visibilidade acerca da importância do profissional da área na sociedade.

Nesse contexto, o professor pode assumir perspectivas de saúde ultrapassadas ou de senso comum, independentemente se compreende a produção histórica das representações de saúde ou se está afastado das discussões acadêmico-profissionais. Embora ainda haja uma dificuldade de encontrar na própria literatura um consenso acerca do conceito de saúde (PALMA; ESTEVÃO; BAGRICHEVSKY, 2003), observa-se que, recentemente, cada vez mais há um crescimento de discussões epistemológicas acerca do assunto (ALMEIDA FILHO, 2011).

A condição de estarem engajados na profissão pode fazer com que o professor, ao envelhecer, reflita sobre os desafios práticos e conceituais concernentes ao corpo e à saúde. Segundo Stano (2001), envelhecer na carreira docente em geral propicia ao professor um desejo incansável de aprender e de se atualizar. Essa ideia vai de encontro à afirmação genérica de Oliveira (2000) ao frisar que os professores de Educação Física, em especial, inseridos há um tempo na prática, tendem a resistir a qualquer forma de mudança, dificultando avanços teórico-práticos. 
Destarte, uma categoria referente ao objetivo da prática profissional, que é naturalizada pelos professores, sobretudo de academias de ginástica, é a saúde como se fosse um objeto a ser adquirido e/ou moldável:

Você só vai conseguir isso (saúde), acho que através do exercício (físico), da atividade física. [...] É, "pra" você não ficar toda hora batendo no médico, no hospital, você tem que fazer exercício físico "pra", como fosse que você tivesse dando uma manutenção "pra" sua saúde. (P5 - Professor de academia de ginástica, 44 anos)

Acho que a gente deveria ganhar muito bem porque a gente tenta manter a saúde das pessoas, não na mesma situação do médico, quando elas vão para o médico é porque elas estão doentes, a gente tenta fazer com que as pessoas não fiquem doentes, eu acho que esse é o meu recado aí. (P8 - Professor de academia de ginástica, 45 anos)

O professor ao trabalhar com as práticas corporais estaria proporcionando saúde ao aluno. A saúde se torna um objeto que pode ser oferecido plenamente de maneira garantida aos sujeitos. Essa visão de enquadrar o corpo em busca eminentemente da saúde ratifica a concepção dualista e persistente da área de Educação Física ao ignorar a globalidade do ser humano. Quando os fenômenos são explicados por leis invariáveis e universais, o corpo acaba sendo visto apenas como uma máquina biológica em que suas partes podem ser manipuladas (LE BRETON, 2003).

A representação de relacionar a saúde exclusivamente ao corpo pode ser explicada pelo fato de historicamente ser um dos apoios dos profissionais em legitimar suas intervenções na sociedade (DA ROS; VIEIRA; CUTOLO, 2005). A autodedicação preventiva e disciplinar do corpo é valorizada por uma imposição de "script" de normas técnico-científicas prescritas por profissionais de Educação Física para uma normalização de um estilo de vida que certamente poderia ser adotado (BAGRICHEVSKY, 2009). A concepção, os saberes e a intervenção profissional dos professores formados há alguns anos que indicam para o aluno um tipo de estilo de vida implica na garantia de que o meio 
seja propício para adoção de estratégias a favor da saúde, situação essa, às vezes, irreal (PALMA; ESTEVÃO; BAGRICHEVSKY, 2003).

Detectou-se que a categoria saúde como se fosse um objeto a ser adquirido e/ou moldável se constituiu como um contraponto à estética corporal:

Eu parei de pensar em estética e passei a pensar em saúde, não que eu não pensasse em saúde, mas eu era assim uma voz, uma única voz no deserto [...] porque eu falava de saúde, mas se saísse do lado estético e das "gostosas da primeira fila" eu poderia até perder o emprego, então, eu tinha que enfatizar o lado estético e hoje não. Hoje eu não "tô" nem preocupado com o lado estético, ele vem em consequência. [...] É de saúde em primeiro lugar. (P1 - Professor de academia de ginástica, 54 anos)

Antigamente acho que as pessoas [...] malhavam muito por causa [...] da coisa estética ou mesmo social, hoje em dia muitos dos alunos, eles têm, continua essa parte (estética) claro, mas eles têm uma consciência mais, que eles sabem que é uma coisa que vai ajudar que [...] "tá" relacionado à saúde, não "tá" relacionado só ao "look" da pessoa. (P4 - Professor de academia de ginástica, 42 anos)

Os professores de academia de ginástica se remetem à saúde como objetivo da prática profissional, tendo a necessidade de destacar que a busca da estética ficaria em segundo plano ou seria até mesmo dispensável. A saúde é vista como algo positivo e a estética, como algo, muitas vezes, negativo. Desse modo, configura-se a crítica sobre o processo de modificações corporais para atender um estereótipo de beleza pré-determinado socialmente. Petry e Garces (2009) identificaram que os professores ao envelhecerem mostram-se cientes de serem incentivadores da prática corporal para a saúde e não somente para fins estéticos.

O professor se depara com uma ideia de corpo em que o desejo exacerbado pela estética corporal é considerado como algo "profano" e a saúde como algo "sagrado". Para Hertz (1980), o corpo não escapa da bipolaridade representada entre o profano e o sagrado, isto é, criase uma tensão entre aquilo que é socialmente repelido e aceitável, respectivamente. Para se enquadrar no que é sagrado e se distanciar do 
que é profano, emergem as práticas corporais nas academias de ginástica. Mesmo depois de anos na prática profissional, o professor se torna a peça central para que o aluno transite do atributo corporal considerado "mau" para o "bom". As diferentes concepções de intervenção profissional na qual a área de Educação Física se pauta/pautava influenciam significativamente os professores, pois estes valorizavam a estética corporal em determinada época e atualmente privilegiam a saúde. O contexto histórico-contextual e a maturidade profissional com o envelhecimento podem interferir na intervenção docente.

A categoria da saúde como se fosse um objeto a ser adquirido e/ou moldável não foi encontrada nos discursos do professor de Educação Física escolar. No âmbito educacional, emergiu uma categoria vinculada primordialmente ao aspecto social:

Acho que o que é mais importante hoje é você tentar influenciar na parte social do aluno, tentando mudar a vida dele [...] tentando você ser uma boa referência "pra" ele, "pra" que ele possa se interessar pelo que você "tá" falando [...] então, acho muito importante, hoje, a gente tem que conquistar o aluno "pra" depois você colocar algum conteúdo de matéria, vamos dizer assim. O mais importante é tentar mudar ele como cidadão, né? Passar alguns conceitos que eles ignoram, né? (P3 Professor de escola, 47 anos)

Eu me baseio muito pelo social, pela integração do grupo, entendeu? [...] eu trabalho com grupo, só grupo misto [...] fazendo esse processo de integração entre meninos e meninas nesse negócio de respeitar o espaço do outro, respeitar a força do outro, as diferenças, essa diferença, trabalho com a diferença entre eles que é muito interessante e a diferença deles comigo também, né? Essa relação é muito rica. (P10 - Professor de escola, 60 anos)

O "social" se refere a valores que deveriam ser trabalhados com os alunos para um bem-viver em sociedade. Já outros professores valorizam o "social" no sentido de socializar e criar um ambiente propício para uma boa convivência interpessoal aluno-aluno e aluno-professor. Tais discursos estariam vinculados a um novo perfil de aluno que, de 
acordo com os professores, possui um volume de conhecimento sobre diversos saberes relacionados à Educação Física e de socialização diferentes de alguns anos atrás. Conforme os entrevistados, o atual nível de conhecimento e o grau de socialização do aluno são distintos, fazendo com que os professores realizem adaptações na sua prática profissional:

No início (da carreira), né? São 20 anos que já se passaram. No início o tipo de aluno que a gente trabalhava [...] respeitavam mais o professor, hoje em dia, "tá" difícil realmente [...] a gente vê realmente, nitidamente, a diferença de comportamento deles (alunos) [...] a minha postura teve que se adequar a nova realidade, né? Você tem que se adaptar a maneira deles (alunos), a gente, da melhor maneira, tenta passar coisas positivas, né? (P3 - Professor de escola, 47 anos)

A relação do aluno lá de trás com você e a relação com o aluno de hoje é completamente diferente, quando você vai falar do handebol como uma coisa nova, os alunos já viram na televisão, já te dão uma resposta e lá (antigamente) não tinha isso [...] então, o seu trabalho tem que ser diferente, você tem que ser muito mais criativo e trabalhar com jovem hoje, ele tem muito mais informação do que tinha na década de (19)70 [...] "pra" você trabalhar com isso é mais difícil, teoricamente, mais difícil, mas é muito mais gratificante, porque você "tá" formando um ser humano muito melhor. (P10 - Professor de escola, 60 anos)

Esses depoimentos estão vinculados a um grupo de professores que se formou nas décadas de 80 e 90 e que sente atualmente a diferença em relação às mudanças no perfil dos alunos, vivenciando um envelhecer profissional, de certa maneira, peculiar. Emerge a ideia de que o aluno faz parte e interage com a sociedade, caracterizando, na intervenção profissional, uma concepção de corpo menos fragmentada e biológica ao evocarem as relações sociais - leia-se corporais. As noções de corpo são construídas social e culturalmente passíveis de modificação conforme a variação do tempo e entre os grupos sociais (LE BRETON, 2003). 
As diretrizes dos Parâmetros Curriculares Nacionais da Educação Física escolar e as legislações que respaldam a área possuem certa preocupação com um "corpo saudável". A ideia da responsabilidade de garantir a saúde pelo movimento na escola e o dever em cuidar do próprio corpo visando à saúde incorporada para toda a vida do aluno também são encontradas na literatura da área (DARIDO; RANGEL, 2005). Já alguns autores (DA ROS; VIEIRA; CUTOLO, 2005) ponderam sobre a necessidade do professor educar de maneira crítica para os fatores que cercam o corpo e a saúde, oferecendo autonomia aos alunos ao demonstrar os fatores de caráter econômico e sociocultural que moldam a ideia de que exercícios físicos são apenas parte do que favorece a saúde. Embora haja esse panorama acadêmico-profissional, os professores de escola, depois de anos na carreira, tentam legitimar a sua intervenção profissional para/o "social", sobrepondo-se, assim, à questão da saúde.

Outra categoria sobre o que nortearia a prática profissional foi o objetivo de qualidade de vida associada à saúde para os alunos.

$\mathrm{Eu}$ acho que a gente tem que focar muito mais as pessoas que realmente precisam do nosso trabalho, não aquelas que acham que nós somos transformadores do mundo, a atividade física na área de qualidade de vida não é transformadora do mundo, ele é um ativador de qualidade de vida e saúde, e nós somos profissionais na área de saúde [...] saúde está ligada à qualidade de vida. (P14 - Professor de academia de ginástica, 45 anos)

Eu olho muito o lado saúde, né, dos alunos. Então, é, eu faço um trabalho, vamos dizer assim, voltado "pra" uma clientela que eu chamo de "normal", embora a outra eu não possa dizer que não seja normal [...] então, eu tenho que preparar ele "pra" viver melhor, quer dizer, melhorar a qualidade de vida dele, né? Então é um trabalho, vamos dizer assim, de intensidade moderada, né? (P15 - Professor de academia de ginástica, 50 anos)

Alguns professores investigados não fizeram distinção entre saúde e qualidade de vida. Segundo Nogueira (2005), houve uma indiscriminada disseminação da relação causal envolvendo exercício-saúdequalidade de vida. Além da complexa trama social e acadêmica que envolve tais construtos, há divergências metodológicas nas pesquisas 
ao tentarem alcançar uma definição sobre tais conceituações. As indefinições conceituais geram diferentes concepções acerca da prática do professor ou retardam um amadurecimento teórico em como se trabalhar com a saúde efetivamente na sua realidade profissional.

Sabe-se que a qualidade de vida é um constructo dinâmico, relativo e polissêmico que deve ser investigado criticamente (MINAYO; HARTZ; BUSS, 2000). Percebe-se que os significados atribuídos à qualidade de vida pelos professores foram distintos. Qualidade de vida pode estar ligada a uma esfera subjetiva como o que os sujeitos podem escolher, acessar e usufruir, ou objetiva, mais vinculada às condições e modo de vida como aspectos socioculturais e econômicos (ALMEIDA; GUTIERREZ; MARQUES, 2009).

A qualidade de vida foi compreendida pelos professores a partir do ponto de vista individual e contextual:

A minha função é desenvolver as qualidades físicas do ser humano [...] é o que eu acho que deveria ser "pra" eles (alunos), o principal, entendeu? [...] E isso "tá" diretamente relacionado com a qualidade de vida, "pra" melhora da qualidade de vida, apesar de que a qualidade de vida "pra" você é uma coisa, "pra" mim é outra, "pra" outra é outra [...] o que se diz hoje no mundo à respeito de qualidade de vida, é você ter uma vida boa, onde você não seja sedentário, que você possa desenvolver suas atividade e sei lá, respirar bem, viver, prolongar mais a sua vida, coisas que proporcionem isso, mas acho que qualidade de vida na realidade é um negócio muito individual de cada um, né? De repente, sei lá, qualidade de vida "pra" você pode ser se drogar, ficar bebendo cerveja, invadir a noite, ir "pra" festas, esbórnias, mulheres, pode ser isso, entendeu? [...] depende, por exemplo, "pra" outro pode ser religião, "pro" outro pode ser política e por aí vai, né? (P5 - Professor de academia de ginástica, 44 anos)

O aluno munir-se-ia de critérios avaliativos em relação à sua qualidade de vida de acordo com suas próprias experiências, expectativas, crenças, vivências e trajetórias, que vão se modificando com o passar dos anos. Minayo, Hartz e Buss (2000) exemplificam que valores como amor, liberdade, solidariedade e inserção social, realiza- 
ção pessoal e felicidade podem constituir o que seria qualidade de vida.

Em contrapartida, houve a noção de alguns professores que ainda desejam por meio da sua intervenção profissional que os alunos alcancem a promoção da qualidade de vida:

Eu acho que o meu trato melhor é esse, eu gosto de ver as pessoas melhorando, melhorando sua qualidade de vida, melhorando seu dia-a-dia, melhorando sua tensão [...] ver as pessoas melhor [...] eu gosto de ver as pessoas melhorando independente do trabalho que está sendo feito. (P8 - Professor de academia de ginástica, 45 anos)

Não se pode pensar o aluno só dentro da academia, tem que pensar no aluno, assim, como um todo, a profissão que ele tem, eu já conheço a maioria (dos alunos), sei onde eles trabalham, sei onde eles moram, então isso tudo, eu tento dar uma qualidade de vida "pra" eles, "pra" eles poderem usufruir lá fora (da academia), entendeu? (P9 - Professor de academia de ginástica, 47 anos)

Nota-se a complexidade de avaliar o quão o professor pode "dar" qualidade de vida para o aluno, uma vez que este constructo é de concepção individual, oscilante e plural. Tal questão ainda não está tão incorporada pelos professores que estão na prática há alguns anos, provavelmente, pelo fato das análises sobre qualidade de vida na Educação Física ainda serem recentes (ALMEIDA; GUTIERREZ; MARQUES, 2009). Nesse sentido, a apropriação do atual debate acerca do que seria qualidade de vida paulatinamente acompanha o processo de envelhecimento dos professores na prática profissional. $\mathrm{O}$ atual conceito de saúde ampliado atravessa a própria noção de qualidade de vida (BRUGNEROTTO; SIMÕES, 2009).

Entre os âmbitos de atuação, houve certa diferença em relação à intervenção profissional ligada à qualidade de vida:

Eu acho que é a melhora de qualidade de vida nesse trabalho ligado à academia e no trabalho de colégio também não deixa de ser uma melhora de qualidade de vida, mas uma coisa mais educacional, uma 
coisa mais de tentar estimular, né? (P2 - Professor de academia de ginástica e de escola, 50 anos)

Eu penso assim: eu procuro "pra" passar "pra" eles (alunos) conceito de que a Educação Física é o início para vislumbrar uma melhora de qualidade de vida "pra" eles. (P6 - Professor de escola, 45 anos)

Como pode ser observado nos trechos supracitados, no âmbito escolar os professores usariam recursos como a conscientização para ampliar a visão do aluno sobre uma "melhora de qualidade de vida". $\mathrm{Na}$ academia de ginástica, os efeitos anatomofisiológicos da própria prática corporal seriam os componentes que proporcionariam tal benefício. Para Devide, Oliveira e Ferreira (2005), independente do local de trabalho, o professor de Educação Física deve estar atualizado em relação ao conceito de saúde e ao que pode ser interpretado por qualidade de vida para discutir e ampliar o compromisso da área para além da promoção da aptidão física.

\section{Conclusões}

Ao analisar e discutir se (e com quais significados) o corpo e a saúde emergem nas relações entre o envelhecimento do professor de Educação Física e sua prática profissional, foi possível observar alguns aspectos interessantes e talvez particulares na área, tanto no âmbito da academia de ginástica, quanto no da escola.

No âmbito da academia de ginástica, os professores privilegiam para os alunos o ganho e a busca da saúde basicamente pela intervenção no corpo a partir de um referencial biomédico. No entanto, há indícios de que essa ideia de prática profissional não foi homogênea durante toda carreira, uma vez que a maioria dos professores ressaltou que a estética antigamente já foi mais valorizada como elemento central da sua intervenção docente. Às vezes associada à saúde, outros professores visam à recente noção de qualidade de vida para o aluno através principalmente da sua prática profissional com/para o corpo.

No âmbito da escola, de maneira aparentemente peculiar, o professor tenta promover o aspecto social do/para o aluno pelo fato de tentar se adaptar e intervir no perfil diferente de aluno das últimas gerações. No caso, a discussão sobre saúde como propósito central da interven- 
ção pedagógica do professores de Educação Física escolar formados há alguns anos parece não ter oportunidade de se concretizar, dado este que se confronta às diretrizes dos próprios Parâmetros Curriculares Nacionais, que reconhecem a saúde como um tema transversal importante para ser trabalhado no currículo escolar.

As singularidades de intervenção profissional entre os âmbitos de trabalho também foram detectadas. Uma diferença foi especificamente na presença marcante da preocupação com a saúde na academia de ginástica, quando comparadas à atuação na escola. Outra distinção foi relacionada à maneira que a qualidade de vida seria tratada com/para os alunos, uma vez que na escola seria por meio da conscientização no cotidiano das aulas e, na academia, através da própria prática corporal. Foi possível detectar que nos discursos dos professores investigados as representações acerca da saúde se sobrepuseram aquelas especificamente relacionadas ao corpo propriamente dito.

Para futuras pesquisas, sobretudo de natureza longitudinal, recomenda-se o acompanhamento ao longo de anos de como o professor de Educação Física vem compreendendo o corpo e a saúde na sua prática profissional, sem desconsiderar as possíveis particularidades envolvidas em cada âmbito de trabalho.

The ageing of the physical education teacher and his professional practice: meanings attributed to body and health

\begin{abstract}
The physical education teacher's conceptions of body and health are no longer homogeneous during the career. This study aims to analyze and to discuss the meanings attributed to body and health in the relations between aging as a physical education teacher and his professional practice. Data were collected by using 22 semi-structured interviews with physical education teachers who used to work in schools and gyms. In the gym, the professional practice used to be linked to aesthetics and nowadays is directed to health and wellness. Concerning the professional practice in schools, the social aspect overlapped the health discussion, probably considering the change of student's profile along the years.
\end{abstract}

Keywords: Aging. Physical Education and Training. Human Body. Health. 
El envejecimiento del profesor de educación física e su práctica profesional: significados atribuidos al cuerpo e a la salud

\section{Resumen}

Se sabe que los significados atribuidos al cuerpo e a la salud por el profesional de Educación Física pueden no ser homogéneo durante la carrera docente. Este estudio tuvo como objetivo analizar y discutir se (y con cuales significados) el cuerpo y la salud emergen en la relaciones entre el envejecimiento del profesor de Educación Física y su práctica profesional. Los datos fueron obtenidos por medio de 22 entrevistas semiestructuradas realizadas con profesores de escuelas y academias. Aunque en la academia la práctica profesional no es más relacionada a la estética corporal y actualmente ha enfocado la salud y calidad de vida, fue detectado que en el ámbito escolar, el aspecto social se superpone a la discusión sobre la salud, por un probable cambio de perfil del alumno.

Palabras clave: Envejecimiento. Educación y Entrenamiento Físico. Cuerpo Humano. Salud.

\section{Referências}

ALMEIDA FILHO, N. O que é saúde? Rio de Janeiro: Editora Fiocruz, 2011.

ALMEIDA, M. A. B.; GUTIERREZ, G. L.; MARQUES, R. F. R. Qualidade de vida como objeto de estudo polissêmico: contribuições da Educação Física e do Esporte. Revista Brasileira de Qualidade de Vida, Ponta Grossa, v. 1, n. 1, p. 15-22, jan./jun., 2009.

BAGRICHEVSKY, M. Del "cuerpo saludable" que se (des)constituye. Revista Brasileira de Ciências do Esporte, Campinas, v. 30, n. 3, p. 191-202, maio, 2009.

BEAUVOIR, S. A velhice: a realidade incômoda. Trad. Heloysa de Lima Dantas. 2. ed. São Paulo: Difel, 1976.

BRUGNEROTTO, F.; SIMÕES, R. Caracterização dos currículos de formação profíssional em Educação Física: um enfoque sobre saúde. Physis: Revista de Saúde Coletiva, Rio de Janeiro, v. 19, n. 1, p. 149172, 2009.

CARVALHO, Y. M. Atividade física e saúde: onde está e quem é o "sujeito" da relação? Revista Brasileira de Ciências do Esporte, Campinas, v. 22, n. 2, p. 9-21, jan., 2001. 
DA ROS, M. A.; VIEIRA, R. C.; CUTOLO, L. R. A. Educação Física: entre o biológico e o social. Há conflito nisto? Motrivivência, Florianópolis, v. 17, n. 24, p. 107-117, jun., 2005.

DARIDO, S. C.; RANGEL, I. C. A. Educação Física na escola: implicações para prática pedagógica. Rio de Janeiro: Guanabara Koogan, 2005.

DEVIDE, F. P.; OLIVEIRA, G. A. S.; FERREIRA, M. S. Ampliando o campo de intervenção da Educação Física escolar a partir da análise da escada da aptidão para toda a vida. Pensar a Prática, Goiânia, v. 8 , n. 1, p. 1-19, jan./jun., 2005.

FOLLE, A. et al. Construção da carreira docente em Educação Física: escolhas, trajetórias e perspectivas. Movimento, Porto Alegre, v. 15, n. 1, p. 25-49, jan./mar., 2009.

HERTZ, R. A preeminência da mão direita: um estudo sobre a polaridade religiosa. Religião e Sociedade, Rio de Janeiro, v. 6, p. 99-128, 1980.

LE BRETON, D. Adeus ao corpo: antropologia e sociedade. Campinas: Papirus, 2003.

MINAYO, M. C. S. Saúde como responsabilidade cidadã. In: BAGRICHEVSKY, M.; et al. (Orgs.) A saúde em debate na Educação Física. v. 2. Blumenau: Nova Letra, 2006. p. 93-104.

MINAYO, M. C. S.; HARTZ, Z. M. A.; BUSS, P. M. Qualidade de vida e saúde: um debate necessário. Ciência \& Saúde Coletiva, Rio de Janeiro, v. 5, n. 1, p. 7-18, 2000.

NOGUEIRA, L. Qualidade de vida no trabalho do professor de Educação Física: reflexões sobre as possibilidades de um novo campo de investigação acadêmica. Arquivos em Movimento, Rio de Janeiro, v. 1, n. 1, p. 75-86, jan./jun., 2005.

OLIVEIRA, A. A. B. Mercado de trabalho em Educação Física e a formação profissional: breves reflexões. Revista Brasileira de Ciência e Movimento, Brasília, v. 8, n. 4, p. 45-50, set., 2000. 
PALMA, A.; ESTEVÃO, A.; BAGRICHEVSKY, M. Considerações teóricas acerca das questões relacionadas à promoção da saúde. In: BAGRICHEVSKY, M.; PALMA, A.; ESTEVÃO, A. (Orgs.) A saúde em debate na Educação Física. Blumenau, SC: Edibes, 2003. p. 1532 .

PETRY, L.; GARCES, S. B. B. A percepção do processo de envelhecimento no contexto de trabalho dos professores de Educação Física. Lecturas en Educación Física y Deportes, Buenos Aires, año 14, n. 132, mayo, 2009. Disponível em: <http://www.efdeportes.com/efd132/a-percepcao-do-processo-de-envelhecimento.htm>. Acesso em 14 set. 2010.

SILVA, A. C.; LÜDORF, S. M. A. Possíveis relações entre corpo, saúde e o envelhecimento do professor de Educação Física. Movimento, Porto Alegre, v. 18, n. 2, p. 187-204, abr./jun., 2012.

STANO, R. C. M. T. Identidade do professor no envelhecimento. São Paulo: Cortez, 2001.

TURATO, E. R. Tratado da metodologia da pesquisa clínico-qualitativa: construção teórico-epistemológica, discussão comparada e aplicação nas áreas da saúde e humanas. 5. ed. Petrópolis, RJ: Vozes, 2011.

Recebido em: 11/07/2012

Revisado em: 20/12/2012

Aprovado em: 07/01/2013

Endereço para correspondência

palma_alexandre@yahoo.com.br

Alexandre Palma

Universidade Federal do Rio de Janeiro

Escola de Educação Física e Desportos

Av. Carlos Chagas Filho, 540

Cidade Universitária

21941-599 - Rio de Janeiro, RJ - Brasil 